\title{
A retrospective analysis of surgery in prestyloid parapharyngeal tumors: lateral approaches vs transoral robotic surgery
}

\author{
David Virós Porcuna ${ }^{1}$, Laura Pardo-Muñoz ${ }^{1}$, Constanza Viña Soria ${ }^{1}$, Viviana Nicastro ${ }^{1}$, \\ Mar Palau Viarnès ${ }^{1}$, and Carlos Pollán Guisasola ${ }^{1}$ \\ ${ }^{1}$ Hospital Universitari Germans Trias i Pujol
}

July 16, 2020

\begin{abstract}
Objective Surgery is the standard treatment for most tumors in the prestyloid parapharyngeal space (PPS) but it can be a challenging procedure because of the anatomical complexity of the area. Prestyloid surgery can be performed with various lateral approaches or with a medial approach using transoral robotic surgery (TORS) - either alone or in combination with a transcervical incision. Here we report our experience in the surgical management of prestyloid PPS tumors. Design We have retrospectively compared results with lateral or medial approaches to surgical resection of prestyloid tumors. Participants Between 2015 and 2020, 28 patients with prestyloid PPS tumors underwent surgery at our center: 14 with lateral approaches, including transcervical, transcervical-parotid, and transcervical-mandibular, 12 with TORS, and two with TORS plus a transcervical incision. Main outcome measures Surgical time, post-surgical complications, length of hospital stay, need for feeding tube, and relapse-free survival in the two patient groups. Results Pleomorphic adenoma was the most frequent tumor and $60.7 \%$ of the tumors were benign. Tumor volume and maximum length were similar in patients undergoing surgery with a lateral approach and in those undergoing TORS. Intraoperative image guidance and ultrasound were used in $33 \%$ of TORS. TORS was associated with less surgical time, fewer complications, and shorter hospital stays. Survival rates were similar in the two groups. Conclusion The medial approach by TORS offers better surgical results in prestyloid tumors than the open lateral approach and can be refined by intraoperative guidance.
\end{abstract}

\section{Key points}

- Surgery of prestyloid tumors is challenging and requires meticulous planning based on tumor and patient characteristics.

- Internal carotid artery position and parotid gland involvement are crucial points to consider in choosing a medial or lateral approach in prestyloid tumors.

- Medial approaches to prestyloid tumor surgery are evolving along with technological evolution.

- A medial approach with TORS achieves superior surgical results in prestyloid tumors than open lateral approaches.

- TORS is feasible and safe for both benign and malignant prestyloid tumors in the hands of experienced surgical teams.

\section{INTRODUCTION}

The parapharyngeal space (PPS) is located lateral to the upper pharynx and medial to the mandible, from the hyoid bone caudally to the skull base. It is an inverted pyramid-shaped space divided into the prestyloid and poststyloid components by the tensorvascular-styloid fascia, running posteriorly from the styloid process to the tensor veli palatini muscle. ${ }^{1}$ PPS tumors account for only $0.5-1 \%$ of head and neck cancers, are generally located in the prestyloid, and are mostly benign. ${ }^{2,3}$ Surgery, the mainstay of treatment, can be challenging due to the PPS anatomical complexity and dense neurovascular network. ${ }^{2-4}$ It is essential to select the 
surgical approach with the least risk of postsurgical complications and the greatest possibility of complete resection, especially in malignant tumors.

Surgical approaches for prestyloid tumors can be classified as lateral or transoral/medial. Multiple lateral approaches have been used alone or in combination, ${ }^{2,3}$ including transcervical, transcervical-parotid, and transcervical-mandibular approaches. In contrast, until relatively recently, the medial approach was limited to small tumors near the constrictor muscle due to the limited visualization of the PPS with this approach. ${ }^{5}$ Over the last few years, however, the medial approach known as transoral robotic surgery (TORS) has become more prevalent. ${ }^{6}$ TORS provides a high-definition visualization of the PPS and allows access to narrow areas, enabling resection to be performed without haptic feedback. Although TORS cannot usually benefit from navigational systems due to soft tissue modification in surgical positioning, it is now recognized as an important surgical option - either alone or combined with a transcervical approach. ${ }^{7}$

Here we report our retrospective analysis of two surgical approaches used in our center for the resection of prestyloid tumors. We compare results using TORS assisted by navigational systems with those using lateral approaches in a series of 28 patients.

\section{MATERIALS AND METHODS}

Study design and patient inclusion

This was a retrospective analysis of prospectively collected data on 28 patients with prestyloid tumors undergoing surgery at our center ([removed for blind peer review]) from February 2015 to February 2020. All patients underwent a clinical examination, magnetic resonance imaging (MRI) and computed tomography (CT). A fine-needle aspiration was taken transorally or transcervically. ${ }^{8}$

The use of the data base was approved by the hospital ethics committee ([removed for blind peer review]) and all individuals included in the study provided their signed informed consent.

Surgery

Lateral approaches

Between 2015 and 2017, prestyloid surgery at our center was based on a lateral approach. The transcervical approach involves a 4-cm transverse skin incision; once the digastric posterior belly and the stylohyoid are recognized, the stylomandibular ligament is cut to improve exposure. The dissection continues toward the head and the inferior and posterior PPS can be exposed. ${ }^{9}$ The trancervical-transparotid approach identifies the facial nerve and reaches the deep parotid lobe and the lateral prestyloid space. ${ }^{10}$ The transcervicaltransmandibular approach adds a mandibular osteotomy, making it possible to reach the upper PPS. Facial nerve intraoperative neuromonitoring using the AVALANCHE system (Dr. Langer Medical GmbH, Waldkirch, Germany) with four channels was used with these lateral approaches.

\section{TORS}

Since 2018, prestyloid surgery at our center has been based on a medial approach with TORS - either alone or in combination with a transcervical incision when necessary - using the da Vinci Xi (Intuitive Surgical, Inc, Sunnyvale, CA) docked at the patient's left side. The oropharyngeal cavity is accessed with the FeyhKastenbauer retractor modified by Wenstein-O'Malley (Olympus Corp). Surgery is performed with a slightly tilted head-up position. A single dose of dexamethasone 4-8 $\mathrm{mg}$ is administered to avoid postoperative airway edema. Prophylactic tracheostomy is not a usual procedure. Patients with postoperative edema or those in whom there are doubts about airway safety remain intubated for 24 hours; if the situation does not improve, a temporary tracheostomy is considered.

TORS starts with 0-30-degree scope and the Endowrist TM instruments (Intuitive Surgical, Inc). ${ }^{6}$ The initial incision is made in the pterygomandibular raphe; once the palatoglossus and constrictor muscles are dissected, the prestyloid PPS is exposed by blunt dissection. ${ }^{11}$ When there is lateral extension, the lateral pterygoideus muscle is cut to expand the axial axis of the surgical corridor. When a lateral extension cannot 
be controlled with TORS alone, it is combined with a transcervical incision (Figures 1-2) to dissect the lateral edge of the tumor.

We use the optical BrainLab as an intraoperative image-guided navigation system with CT and/or MRI images. The pterygoid plates, styloid process, and first cervical vertebrae are used as a guiding reference. The head fixation is done by fixing the array with a clamp to the head holder or to the mouthgag-fixation-bed block without using the head holder (Figure 3). The registration process is based on a point correlation technique. Navigation is performed using the optical tracking system with the soft-touch pointer.

We use a second navigation system based on ultrasound guidance using a $20 \mathrm{MHz}$ disposable doppler probe (Mizuho Medical Co. Ltd.) to identify vascular structures.

Swallowing assessment

Prior to hospital discharge, functional assessment of swallowing is performed by fiberoptic endoscopic evaluation of swallowing and/or video fluoroscopy in the dysphagia unit of our center. Patients are evaluated as to whether they should receive a normal diet, diet adaptation, or swallowing rehabilitation or if they should keep the feeding tube. The same evaluation is performed at 3 and 6 months after surgery.

Data collection and statistical analysis

We collected data on tumor extension, surgical margins, associated procedures, nasogastric tube and/or gastrostomy, length of hospitalization, complications, need for adjuvant treatment, and swallowing. Descriptive statistics were used to summarize data. The Chi-square test or the Fisher's exact test, as appropriate, was used to determine an association between categorical variables. The one-way analysis of variance or the independent sample t-test was used to determine differences between means. We tested for normality using the Shapiro-Wilk test of normality and for homogeneity of variances using Levene's test. The Kruskal-Wallis or the Mann-Whitney U non-parametric tests were used when the normality assumption was not met. Survival curves were estimated using the Kaplan-Meier method. All statistical analyses were performed with Stata, version 14.2 software (StataCorp LLC). Significance was set at $P$ [?] .05.

\section{RESULTS}

\section{Patient characteristics}

The study included 28 surgically resected patients with prestyloid PPS tumors. Between 2015 and 2017, 14 patients were treated with a lateral approach. Between 2018 and 2020, 14 were treated with a medial approach. Thirteen tumors $(46.4 \%)$ originated in the deep lobe of the parotid gland. Seventeen $(60.7 \%)$ were benign. Patient and tumor characteristics are shown in Table 1.

\section{Navigation}

Dual system intraoperative navigation was used in five procedures with TORS. The ultrasound system helped to identify the carotid vessels in all five cases. The Brain Lab optical system was not able to achieve optimal registration in three cases, while in the other two cases, it helped to identify the pterygoid plates, the styloid process and the PPS.

\section{Outcomes}

The mean duration of surgery was longer for lateral than for medial approaches $(P=.02)$ (Table 1$)$. Post-surgical complications were more frequent with lateral approaches $(P=.01)$, with the highest rate (72\%) associated with the transcervical-transparotid approach, due to postoperative facial palsy. The only complications associated with TORS were one case of cervical hematoma and one of pharyngeal wound dehiscence with temporary velopharyngeal incompetence (Tables 1 and 2). The free margin rate was $75 \%$ for both approaches.

Four patients in each group required a feeding tube. The mean time in those treated with a lateral approach was 2.6 days, while the two undergoing transcervical-transmandibular surgery required a tube for a mean of 
13 days. The mean time in those treated with a medial approach was 1.9 days, while the patient undergoing TORS + transcervical required a tube for five days.

The mean length of hospital stay overall was similar with both approaches $(P=.19)$ (Table 1$)$. Among patients treated with a medial approach, hospital stay was longer in those with post-surgical complications than in those without (12 vs 4.75 days; $P=.01$ ). With a lateral approach, length of hospital stay was similar for those with and without complications (9 vs 8.6 days; $P=.93$ ).

With a median follow-up of 32 months (range, 4-60), there were no significant differences in 2-year relapse-free survival rates between the two groups (Table 1 ).

\section{DISCUSSION}

The main objectives of surgical excision of prestyloid tumors are to relieve symptoms, prevent imminent morbidity, and avoid malignant transformation, especially in pleomorphic adenomas. However, there are often complications following surgical treatment of benign tumors due to the anatomical complexity of the area. ${ }^{4}$ The ideal surgical approach should allow enough room to achieve a complete resection while still controlling the nearby neurovascular structures and managing possible complications.

The direct pathway to the prestyloid is a medial approach, which has been used since the $1950 \mathrm{~s} .{ }^{12}$ Until recently, however, this approach was controversial since the limited visibility and narrow working area often led to increased tumor spillage and recurrence and to the risk of neurovascular injury. ${ }^{13}$ TORS was first described in $2007^{6}$ and has since evolved as a valid approach, ${ }^{14}$ with improved visual magnification and the precision of robotic instruments. Today, TORS is able to open a wide corridor in the middle PPS, thus minimizing the risk to neurovascular structures. ${ }^{9}$ However, the use of TORS is less than optimal in tumors located in the far lateral and posterior areas of the PPS, ${ }^{6}$ and in cases with lateral extension due to parotid gland primary involvement, it can be combined with a transcervical approach. ${ }^{9,14,15}$

While some decision-making algorithms for choosing between different lateral approaches have been proposed, ${ }^{16}$ there are no clear guidelines for deciding between lateral, medial, or combined approaches. We have developed a decision-making algorithm for surgical approaches to prestyloid tumors based on the position of the internal carotid artery and parotid involvement on the lateral tumor extension (Figure 1). Based on this algorithm, we now use a medial approach in the vast majority of prestyloid tumors.

The skills and experience of the surgical team are crucial when selecting the best approach to prestyloid tumors. ${ }^{17}$ In this study, the same surgical team used both the lateral and medial approaches, though at different time periods. We found no differences in tumor size, pathology, or patient age between the two groups of patients, and in line with previous reports, ${ }^{3,16}$ tumors in both groups were primarily benign salivary gland tumors. The medial approach proved superior in terms of duration of surgery, length of hospital stay, and post-surgical complications. The lateral approach required a longer surgical time despite the extra time needed for docking the da Vinci system in the medial approach, most likely because the medial approach provides the most direct corridor to the prestyloid PPS. ${ }^{4,9}$ Length of hospital stay was shorter with a medial approach, perhaps due to the more direct route and fewer associated complications, ${ }^{9,14,18}$ as well as to a potential time bias since the two groups were treated in different years. Post-surgical complications were less frequent with the medial approach, possibly due to less structure dissection. ${ }^{9}$

The most common lateral approach for prestyloid tumors is transcervical, ${ }^{2,3}$ but this is not ideal if the tumor is in the upper PPS. The transcervical approach is often used in conjunction with a transparotid approach when the tumor is located in the deep lobe of the parotid, though this increases the risk of involvement of the facial nerve. Previous studies have reported a complication rate of $20-40 \%$ with these approaches. ${ }^{2,3} \mathrm{~A}$ transmandibular approach, combined with the transcervical approach, was first proposed for patients with suspected malignant tumors, very large tumors, or vascular tumors ${ }^{19}$ and is now used in $3-40 \%$ of cases ${ }^{2,3}$ although it is associated with increased complications. ${ }^{2,3,8}$ This approach may require a covering tracheostomy, longer hospital stay, and delay in oral nutrition, and carries additional risks of mandibular dehiscence, temporomandibular joint dysfunction, and loss of dentition. These combined lateral 
approaches achieve sufficient working space and vascular control but are associated with high rates of postsurgical complications. ${ }^{2,3}$ In our series, we observed complications in $64.3 \%$ in patients treated with a lateral approach, mainly due to facial mobilization associated with the transcervical-transparotid approach, which led to permanent facial palsy in $35 \%$ of cases. The transcervical-transmandibular approach was associated with a longer hospital stay and greater need for a feeding tube. In contrast, TORS has been reported to have only $7-17 \%$ complications, ${ }^{14}$ with hematoma and pharyngeal dehiscence being the most common. In our series, the medial approach was associated with complications in only two cases: one pharyngeal dehiscence with temporary velopharyngeal incompetence and one cervical hematoma.

The disadvantages of TORS are the lack of haptic feedback and the limited space in the deep PPS without control of carotid vessels. However, image-guided surgery, though not yet in widespread use, is improving these conditions ${ }^{20}$ and is a promising tool for reducing complications associated with TORS. ${ }^{20-22}$ In our practice, we use two intraoperative assessment methods: an image-based navigational system and ultrasound guidance. Pre-surgical image-based navigational systems are known to be accurate, particularly in fixed bone frameworks. Although the PPS is made up of soft tissues, they are not very mobile. Moreover, the skull base, pterygoids, styloid processes, and first cervical vertebrae are near the PPS, which makes intraoperative navigation feasible. A limitation to this system is the need to fix the head to the reference system. This can be done in the standard way, by fixing the array with a clamp to the headholder, which is more stable and offers more precision, or alternatively, by screwing the array to the skull, which allows better mobilization of the patient if necessary. We have also used a fixation to the mouthgag-fixation-bed block (Figure 3), which allows more flexibility in the placement of the star, which can then be somewhat separated from the head to facilitate docking of the da Vinci system. However, this method requires a small sacrifice in navigational precision. Our second navigation system is based on ultrasound guided by a doppler $20 \mathrm{MHz}$ probe with 1 $\mathrm{cm}$ of tissue penetration to identify the external branches of the facial and lingual arteries and the internal carotid artery. We plan to increase our initial experience with image-guided systems and further investigate navigation systems before drawing definite conclusions. Nevertheless, based on our good surgical results with medial approaches, we can recommend them for selected prestyloid PPS tumors. Those with the internal carotid artery in a lateral position can benefit from a medial approach with TORS. When there is a lateral extension due to a primary parotid tumor, a combined approach is required to reach the external area. If this prolongation does not involve the parotid gland, TORS alone can be considered.

\section{CONCLUSIONS}

Surgery for prestyloid tumors is evolving in parallel with technology. At present, however, despite multiple reports, ${ }^{2,3,14,23}$ there are no specific guidelines for selecting TORS or lateral approaches. In the present single-center study of two surgical approaches to these tumors, we have found superior surgical results with medial approaches using TORS or TORS combined with a transcervical approach. TORS can be improved with intraoperative image guidance, and further investigation of these techniques is warranted.

\section{REFERENCES}

1. Stambuk HE, Patel SG. Imaging of the parapharyngeal space.Otolaryngol Clin North Am. 2008;41(1):77101, vi.

2. Kuet ML, Kasbekar AV, Masterson L, Jani P. Management of tumors arising from the parapharyngeal space: A systematic review of 1,293 cases reported over 25 years. Laryngoscope.2015;125(6):1372-1381.

3. Riffat F, Dwivedi RC, Palme C, Fish B, Jani P. A systematic review of 1143 parapharyngeal space tumors reported over 20 years. Oral Oncol. 2014;50(5):421-430.

4. Mirapeix RM, Tobed Secall M, Pollan Guisasola C, et al. Anatomic Landmarks in Transoral Oropharyngeal Surgery. J Craniofac Surg.2019;30(2):e101-e106.

5. Pang KP, Goh CH, Tan HM. Parapharyngeal space tumours: an 18 year review. J Laryngol Otol. 2002;116(3):170-175. 
6. O'Malley BW, Jr., Weinstein GS. Robotic skull base surgery: preclinical investigations to human clinical application. Arch Otolaryngol Head Neck Surg. 2007;133(12):1215-1219.

7. Duek I, Amit M, Sviri GE, Gil Z. Combined endoscopic transcervical-transoral robotic approach for resection of parapharyngeal space tumors. Head Neck. 2017;39(4):786-790.

8. Lopez F, Suarez C, Vander Poorten V, et al. Contemporary management of primary parapharyngeal space tumors. Head Neck.2019;41(2):522-535.

9. Ferrari M, Schreiber A, Mattavelli D, et al. Surgical anatomy of the parapharyngeal space: Multiperspective, quantification-based study.Head Neck. 2019;41(3):642-656.

10. Bradley PJ, Bradley PT, Olsen KD. Update on the management of parapharyngeal tumours. Curr Opin Otolaryngol Head Neck Surg.2011;19(2):92-98.

11. Dallan I, Seccia V, Muscatello L, et al. Transoral endoscopic anatomy of the parapharyngeal space: a step-by-step logical approach with surgical considerations. Head Neck. 2011;33(4):557-561.

12. Boyce BJ, Curry JM, Luginbuhl A, Cognetti DM. Transoral robotic approach to parapharyngeal space tumors: Case series and technical limitations. Laryngoscope. 2016;126(8):1776-1782.

13. Carrau RL, Myers EN, Johnson JT. Management of tumors arising in the parapharyngeal space. Laryngoscope. 1990;100(6):583-589.

14. Chan JY, Tsang RK, Eisele DW, Richmon JD. Transoral robotic surgery of the parapharyngeal space: a case series and systematic review. Head Neck. 2015;37(2):293-298.

15. Duek I, Sviri GE, Billan S, Gil Z. Minimally Invasive Surgery for Resection of Parapharyngeal Space Tumors. J Neurol Surg B Skull Base. 2018;79(3):250-256.

16. Prasad SC, Piccirillo E, Chovanec M, La Melia C, De Donato G, Sanna M. Lateral skull base approaches in the management of benign parapharyngeal space tumors. Auris Nasus Larynx.2015;42(3):189-198.

17. Eisele DW, Richmon JD. Contemporary evaluation and management of parapharyngeal space neoplasms. J Laryngol Otol.2013;127(6):550-555.

18. Chu F, Tagliabue M, Giugliano G, Calabrese L, Preda L, Ansarin M. From transmandibular to transoral robotic approach for parapharyngeal space tumors. Am J Otolaryngol. 2017;38(4):375-379.

19. Ariel IM, Jerome AP, Pack GT. Treatment of tumors of the parotid salivary gland. Surgery. 1954;35(1):124-158.

20. Rosenthal EL, Warram JM, Bland KI, Zinn KR. The status of contemporary image-guided modalities in oncologic surgery. Ann Surg. 2015;261(1):46-55.

21. Viros Porcuna D, Pollan Guisasola C, Vina Soria C, et al. Transoral robotic surgery for squamous cell carcinoma of the oropharynx in a primarily human papillomavirus-negative patient population. Clin Transl Oncol. 2020;22(8):1303-1311.

22. Paydarfar JA, Wu X, Halter RJ. Initial experience with image-guided surgical navigation in transoral surgery. Head Neck.2019;41(1):E1-E10.

23. De Virgilio A, Costantino A, Mercante G, Di Maio P, Iocca O, Spriano G. Trans-oral robotic surgery in the management of parapharyngeal space tumors: A systematic review. Oral Oncol. 2020;103:104581.

Table 1. Patient and tumor characteristics and surgical outcomes in 28 patients with prestyloid tumors

\begin{tabular}{llll}
\hline & $\begin{array}{l}\text { All Patients } \mathbf{N = 2 8} \\
\text { N (\%) }\end{array}$ & $\begin{array}{l}\text { Lateral Approach } \\
\text { N=14 N (\%) }\end{array}$ & $\begin{array}{l}\text { Medial Approach } \\
\mathbf{N = 1 4} \mathbf{~ N ~ ( \% ) ~}\end{array}$ \\
\hline Age, yrs Median (range) & $60.18(34-85)$ & $62.36(42-85)$ & $58(34-76)$
\end{tabular}




\begin{tabular}{|c|c|c|c|}
\hline & $\begin{array}{l}\text { All Patients } \mathrm{N}=\mathbf{2 8} \\
\mathrm{N}(\%)\end{array}$ & $\begin{array}{l}\text { Lateral Approach } \\
\mathrm{N}=14 \mathrm{~N}(\%)\end{array}$ & $\begin{array}{l}\text { Medial Approach } \\
\mathrm{N}=14 \mathrm{~N}(\%)\end{array}$ \\
\hline $\begin{array}{l}\text { Sex Male Female } \\
\text { Surgical approach } \\
\text { Transcervical } \\
\text { Transcervical- } \\
\text { transparotid } \\
\text { Transcervical- } \\
\text { transmandibular } \\
\text { TORS alone TORS + } \\
\text { transcervical }\end{array}$ & $\begin{array}{l}15(53.57) 13(46.43) \\
-1(3.57) 11(39.28) 2 \\
(7.14) 12(42.85) 2 \\
(7.14)\end{array}$ & $\begin{array}{l}8(57.1) 6(42.9) \\
1(7.14) 11(78.57) 2 \\
(14.29)--\end{array}$ & $\begin{array}{l}7(50) 7(50) \\
---12(85.71) 2 \\
(14.29)\end{array}$ \\
\hline $\begin{array}{l}\text { Pathology of tumor } \\
\text { Pleomorphic adenoma } \\
\text { Warthin's tumor } \\
\text { Carcinoma ex } \\
\text { pleomorphic adenoma } \\
\text { Adenoid cystic } \\
\text { carcinoma Salivary } \\
\text { duct carcinoma } \\
\text { Schwannoma } \\
\text { Hemangioma Lipoma } \\
\text { Histiocytoma } \\
\text { Metastasis of squamous } \\
\text { cell carcinoma } \\
\text { Myoepithelioma } \\
\text { Lymphoepithelial } \\
\text { lesion Liposarcoma }\end{array}$ & $\begin{array}{l}8(28.57) 1(3.57) 2 \\
(7.14) 1(3.57) 1(3.57) \\
1(3.57) 2(7.14) 1 \\
(3.57) 1(3.57) 7(25.0) \\
1(3.57) 1(3.57) 1 \\
(3.57)\end{array}$ & $\begin{array}{l}6(42.85) 1(7.14) 1 \\
(7.14) 1(7.14) 1(7.14) \\
----2(14.28) 1 \\
(7.14)-1(7.14)\end{array}$ & $\begin{array}{l}2(14.28)-1(7.14)-- \\
1(7.14) 2(14.28) 1 \\
(7.14) 1(7.14) 5(35.7) \\
-1(7.14)-\end{array}$ \\
\hline $\begin{array}{l}\text { Type of tumor } \\
\text { Benign Malignant }\end{array}$ & $17(60.71) 11(39.29)$ & $9(64.29) 5(35.71)$ & $8(57.14) 6(42.86)$ \\
\hline $\begin{array}{l}\text { Mean tumor size, } \\
\mathrm{cm}^{3}\end{array}$ & 19.4 & 21.66 & 17.15 \\
\hline $\begin{array}{l}\text { Mean max tumor } \\
\text { length, cm }\end{array}$ & 3.75 & 3.6 & 3.9 \\
\hline $\begin{array}{l}\text { Need for feeding } \\
\text { tube }\end{array}$ & $8(28.6)$ & $4(28.6)$ & $4(28.6)$ \\
\hline $\begin{array}{l}\text { Mean duration of } \\
\text { surgery, mins } \\
\text { (range) }\end{array}$ & $182.9(40-340)$ & $221.4(100-340)$ & $133.3(40-240)$ \\
\hline $\begin{array}{l}\text { Mean length of } \\
\text { hospital stay, days }\end{array}$ & 7.32 & 8.9 & 5.8 \\
\hline $\begin{array}{l}\text { Rate of } \\
\text { post-surgical } \\
\text { complications }\end{array}$ & $39.3 \%$ & $64.3 \%$ & $14.3 \%$ \\
\hline Free margin rate & $75 \%$ & $75 \%$ & $75 \%$ \\
\hline $\begin{array}{l}\text { 2-year relapse free } \\
\text { survival rate }\end{array}$ & $74.1 \%$ & $69.3 \%$ & $78.6 \%$ \\
\hline
\end{tabular}

Table 2. Post-surgical complications for all patients and according to the surgical approach used 


\begin{tabular}{llll}
\hline Complication & $\begin{array}{l}\text { All Patients } \mathbf{N = 2 8 ~ N} \\
(\mathbf{\%})\end{array}$ & $\begin{array}{l}\text { Lateral Approach } \\
\mathbf{N = 1 4} \mathbf{~ N} \text { (\%) }\end{array}$ & $\begin{array}{l}\text { Medial Approach } \\
\mathbf{N = 1 4} \mathbf{~ N} \text { (\%) }\end{array}$ \\
\hline None & $17(60.7)$ & $5(35.7)$ & $12(85.7)$ \\
Wound dehiscence & $1(3.6)$ & $1(7.1)$ & 0 \\
Transient facial palsy & $2(7.1)$ & $3(21.4)$ & 0 \\
Permanent facial palsy & $5(17.8)$ & $5(35.7)$ & 0 \\
Cervical hematoma & $1(3.6)$ & 0 & $1(7.1)$ \\
$\begin{array}{l}\text { Pharyngeal wound } \\
\text { dehiscence }\end{array}$ & $1(3.6)$ & 0 & $1(7.1)$ \\
\hline
\end{tabular}

\section{Figure Legends}

Figure 1. Decision-making tree for surgical approaches in prestyloid PPS tumors.

ICA, internal carotid artery; TO, Transoral

Figure 2. MRI axial and coronal slices showing prestyloid PPS tumors. A and B:Independent parotid gland tumors treated with TORS. C andD: Prestyloid tumor with lateral extension due to primary parotid involvement treated with TORS in combination with a transcervical approach.

Figure 3. Intraoperative image-guided navigation system with fixed array surgical disposition.

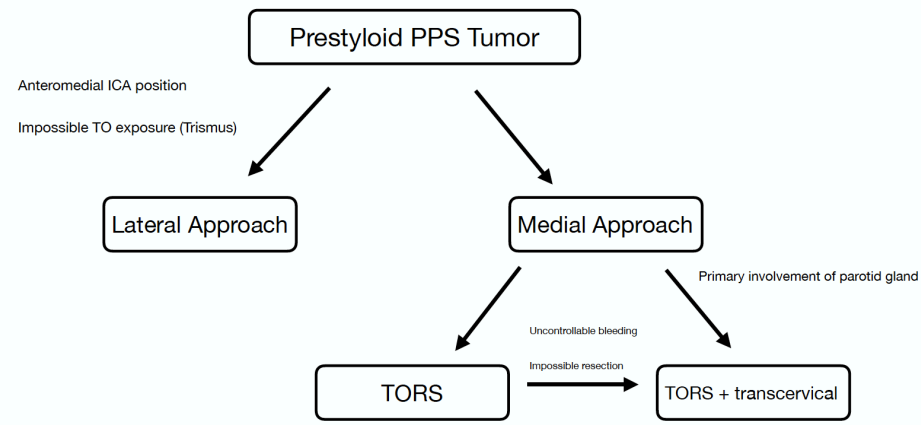

Figure 1. Decision-making tree for surgical approaches in prestyloid PPS tumors.

ICA, internal carotid artery; TO, Transoral 


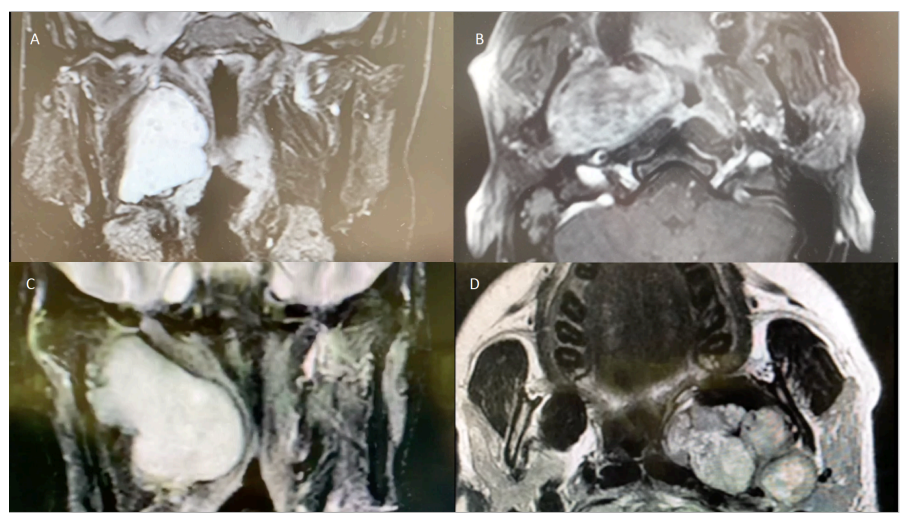

Figure 2. MRI axial and coronal slices showing prestyloid PPS tumors. A and B: Independent parotid gland tumors treated with TORS. C and D: Prestyloid tumor with lateral extension due to primary parotid involvement treated with TORS in combination with a transcervical approach.

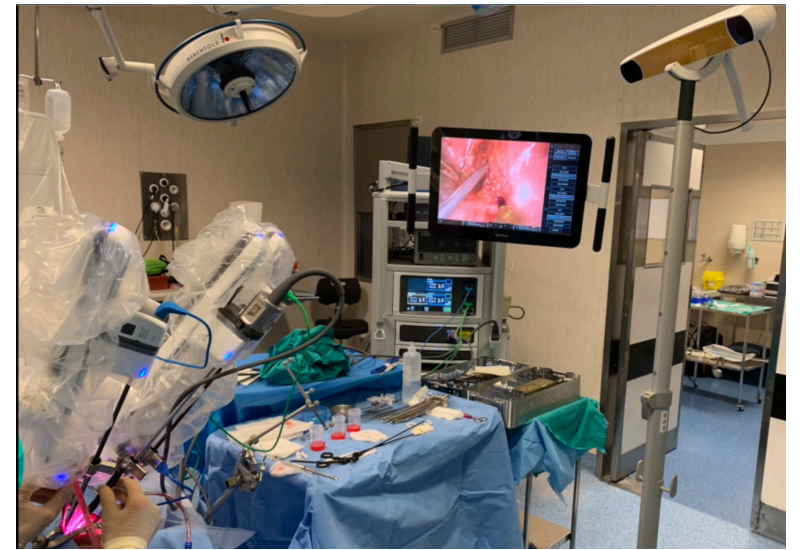

Figure 3. Intraoperative image-guided navigation system with fixed array surgical disposition.

\section{Hosted file}

Table 1.docx available at https://authorea.com/users/342810/articles/469627-a-retrospectiveanalysis-of-surgery-in-prestyloid-parapharyngeal-tumors-lateral-approaches-vs-transoralrobotic-surgery

\section{Hosted file}

Table 2.docx available at https://authorea.com/users/342810/articles/469627-a-retrospectiveanalysis-of-surgery-in-prestyloid-parapharyngeal-tumors-lateral-approaches-vs-transoralrobotic-surgery 